\title{
World webs
}

Andrew Goudie

Geoecology: An Evolutionary Approach. By Richard John Huggett. Routledge: 1995. Pp. 320. £50, \$65 (hbk); £16.99, $\$ 24.95$ (pbk).

PHYSICAL geography, at least in its crudest form, often used to be characterized by various tendencies that included description, classification and compartmentalization. Typically, a textbook would have a series of discrete chapters (on, for example, soils, vegetation and landforms) that had all too little relationship to one another.

In the past two decades, physical geography has been transformed and has regained an interest in one of the fundamental tenets of the discipline: interrelationships. There are various reasons for this transformation, among them the adoption of systems-thinking, the worry about the many ramifications of global and more local environmental changes (whether naturally or anthropogenically induced) and a more balanced concern about the different components of physical geography (leading to a resurgence in biogeography).

Richard Huggett has written a series of books relating to these developments, and Geoecology is his latest. The message of this well produced and well written book is that not only do animals, plants and soil interact with one another, but they also interact with the atmosphere, hydrosphere, troposphere and biosphere to produce landscape systems or geoecosystems. Geoecology is the study of the structure and function of geoecosystems at a variety of scales. The core of the book relates to the "internal influences" that mould geoecosystems, and explores the links between climate and soils, climate and life as well as the influence of altitude, substrate, topography and insularity. It concludes with a consideration of "external influences" (that is, types of disturbance).

The book is geared towards "upper level students and academics". Those taking and teaching courses in physical geography or environmental science will greatly profit from using it, as long as they have first assembled some of the building blocks of their trade from the older genre of textbooks. One of the dilemmas for university teachers of physical geography is that some of the school syllabuses increasingly produce students who have not assembled the building blocks to allow them to gain the stimulus that they could and should get from this informative, intriguing and idiosyncratic volume.

Andrew Goudie is in the School of Geography, University of Oxford, Mansfield Road, OXford OX1 3TB, UK.

\section{The harmonies of nature}

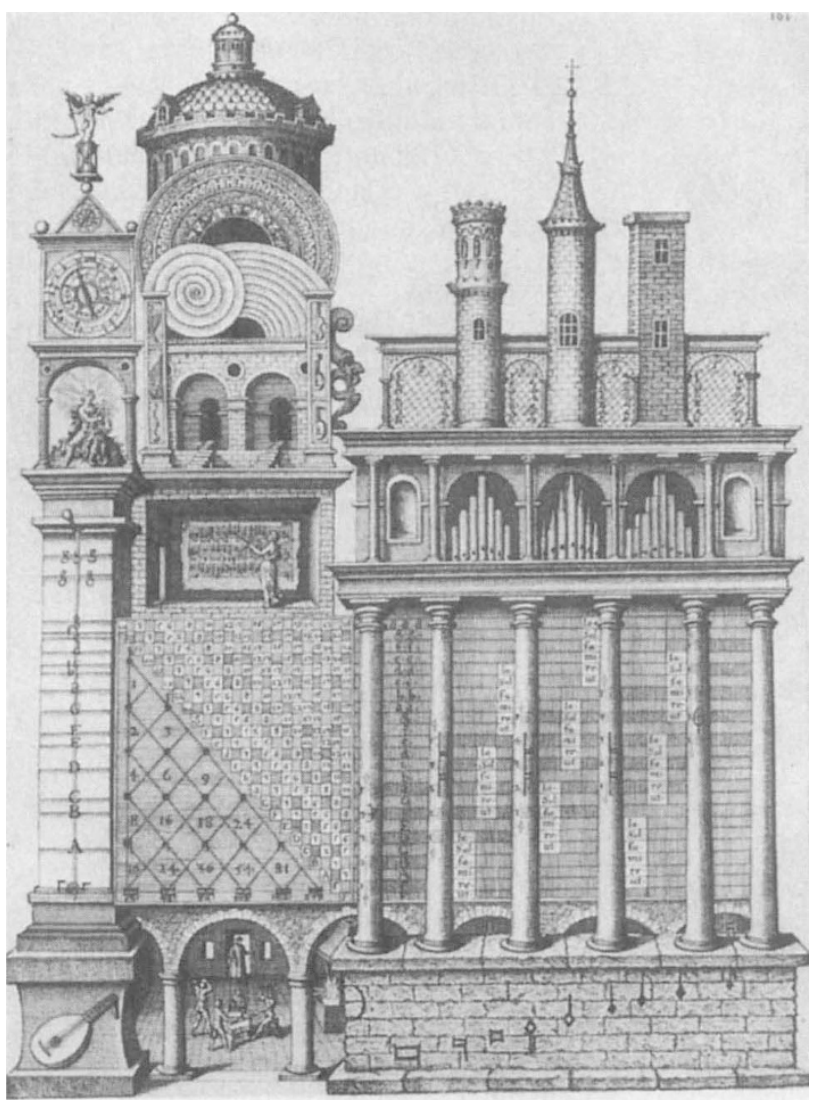

ROBERT Fludd, the
seventeenth-century
English doctor and
occult philosopher,
wrote a series of vast
and beautifully
illustrated treatises in
which he attempted to
reveal the underlying
harmony and
congruity between the
Universe (the
"macrocosm") and
man (the
"microcosm"). This
picture, "The Temple
of Nature", was
intended to be a
mnemonic aid that
enabled adepts to
memorize the basics
of music theory. It is
taken from The Music
of the Spheres by
Jamie James, an
elegantly written
reassessment of the
Western musical
tradition and its
relation to science.
First published in
1993 , the book is now
issued in paperback
by Copernicus, a new
imprint of Springer
(New York). Price is
$\$ 13$.

ROBERT Fludd, the English doctor and occult philosopher, wrote a series of vast reveal the underlying harmony and congruity between the man (the "microcosm"). This of Nature", was intended to be a mnemonic aid that d adepts to of music theory. It is taken from The Music of the Spheres by Jamie James, an elegantly written Western musical tradition and its relation to science. First published in 1993 , the book is now $\$ 13$.

\section{The uses of mathematics}

\section{W. Kilmister}

On the Shoulders of Giants. By Malcolm E. Lines. Institute of Physics Publishing: 1994. Pp. 288. £49.50, $\$ 90$ (hbk); $£ 15$, $\$ 30$ (pbk).

THIS book sets new standards in the popularization of both mathematics and physics. The author has been motivated to write by his puzzlement over the "unreasonable usefulness" of mathematics in physics, and it is the driving force of this puzzle that makes the book so good. Although the author has no answers to the problem, he successfully displays, for those with only a modest knowledge of either subject, 12 historical perspectives that show its acuteness.

All the stories he tells make the point well, but naturally some are less exciting than others. "From Euclid to general relativity" is a fairly standard run through the discovery of non-Euclidean geometries, and "From integers to quaternions" has little physical content beyond the representation of spatial rotations, which had been part of the mathematical drive anyway. But the best of the others are gems; I particularly like "From Aristotle to the structure of glass", which begins with a careful explanation of the problem of packing space with regular solids and the long history of trying to do so with regular tetrahedra, and which then, after a good description of crystallography, goes on to the problem of closest packing of spheres and so on to glasses. This chapter is nicely complemented by one on tiling, which takes the reader through irregular tiling to quasicrystals. The author does not neglect the latest fashions of chaos, fractals and superstrings and he has something new to say about probability and topology.

The treatment of topology in fact illustrates just how well the book succeeds, with the author tracing his way from the familiar bridges of Königsberg through the four-colour theorem to space-filling polyhedra (Voronoi polyhedra) and finally to polymers and glasses again. Such cross-referencing gives the book a satisfying unity.

C. W. Kilmister, emeritus professor of mathematics at King's College, London, is at Red Tiles Cottage, HIgh Street, Barcombe, Lewes BN8 5DH, UK. 